\title{
Research on Key Technology of Enterprise Information Management System
}

\author{
Dong Xin ${ }^{\mathrm{a}}$, Hongxia Zhao ${ }^{\mathrm{b}}$, Baogang Zhou ${ }^{\mathrm{c}}$ \\ School of Management, Bohai University, Jinzhou, P.R. China \\ adxbhdx@163.com, b64071435@qq.com, ${ }^{\mathrm{c}}$ 80891137@qq.com
}

\begin{abstract}
Keywords: Information technology; ASP.NET technology; theoretical basis; SQL server; management system
\end{abstract}

\begin{abstract}
With the rapid development of information technology, information technology has become a reflection on the economic development of country, regions and society, produces significant and profound influence on the way that people live and work, so the key technology of enterprise information management systems studied in this paper is important. This paper firstly studies the theoretical foundation of enterprise information management systems, including system design objectives and development principles; secondly, on the basis of design ideas researches system development techniques, namely ASP.NET technology; finally studies database technology of systems, the main research is SQL Server database technology. Enterprise information management maximize using existing resources improves the quality of the production and operation of enterprises and access to the economic benefits, so the design of enterprise information management system promotes the development of enterprises.
\end{abstract}

\section{Introduction}

With the accelerated development of information technology and business, traffic and information exchange gradually increased for enterprises, it urgently needs to expand the corresponding business and corresponding functions of information management system in order to better serve the entire enterprise. In order to make information management system resources highly unified, highly integration, usability better, highly reusability, scalability stronger, much needed to develop and deploy of information management systems in an excellent platform. Enterprise information management system is a special information management system (MIS), is a method in which the enterprise with advanced information technology collects, collates, processes, spreads, storages and uses information, is a decision support system that of strategically planning business process information activities, planning, organizing, leading and controlling the elements of information activities [1].

Traditional information management systems are only statistics and analysis some properties of the data, they have been unable to meet the needs of information management, processing and analysing for the various sectors, the management, processing and analysing of a large number of spatial data has become a common problem modern information management systems are facing [2], the enterprise information management system studied in this paper is a improvement and innovation on the basis of traditional information systems, using the JSP.NET development technology that with advanced technology and sophisticated features, database technology adopts SQL Server database, it is a relational database management system that can handle large amounts of data, has the features of good scalability and high integration.

\section{Theoretical Basis}

The enterprise information management system studied in this paper is mainly based on the business needs in the actual project development to achieve the following objectives, easy to operate, simple and elegant interface; achieves sub-user roles and permissions management; provide personnel management function, including employee records management, employee mobility 
management, employee training management, employee incentive management, employee appraisal management and sector management; provides customer management functions, including maintenance for customer information; provides project management functions, including project creation, personnel grouping, project notes; provides contract management functions, including approval, contract creation and other contracts; provides payroll management functions, including employee wages classification, account management; provides enterprise bulletin management functions, including bulletin review, announcement statistics, announcement; provides conference management functions, including meetings schedule, meeting records; provides system maintenance functions, including personal information management, user management; systems have higher security.

Development of information management systems should follow the following principles: (1) the principle of security, information systems security directly affect the functionality of the system, and therefore should be considered security issues separately from hardware and software; (2) effective principle, referring to information should associate with the business process in the accurate, consistent and usable manner; (3) easy to use principle that information classification reasonable, friendly interface; (4) advancement principles, mainly manifested in the technology using of advanced and mature .NET development architecture, object-oriented design methods, visual and object-oriented development tools; (5) the principle of scalability and maintainability, to adapt to the future development the system should have good scalability and maintainability; (6) the principles of standardization, standardization mainly refers to software designed strictly enforce national standards related to software engineering, guarantees systems quality; (7) the principle of compatibility and inheritance, compatibility is the ability to achieve organic docking with existing systems, inheritance is that can inherit the data in the original system [3].

\section{ASP.NET Technology}

ASP.NET is built on the basis of .NET platform architecture, on the back-end server provides robust enterprise-level Web application services programming framework for users, is a the server-side scripting technology that embed a web page script can executed by Internet server, it can be created dynamically on a Web server via HTTP requesting documents, its predecessor is ASP (Active Server Pages) technology [4]. ASP.NET architecture including user layer, business logic, data layer three-tier structure, in which the user layer responsible for interacting with the user, receiving user input and presenting data from the server to the customer. Business logic layer responsible for receiving requests come from browser and coming requests to the data layer, meanwhile sending the request processing results to the browser, which consists of Web forms and XML Web Services and component service, Web forms is an core of ASP.NET application, is a base presented to the customer data and information, and is also a base of responding and handling information and data generated when customer interactions with Web forms. Data layer is manipulated data by ADO.NET to provide data services for business logic layer, such as storing data operating results, returning data searching results and others, in the data layer, in order to improve the performance of application, you can introduce a stored procedure [5]. ASP.NET system structure is shown in Fig. 1. 


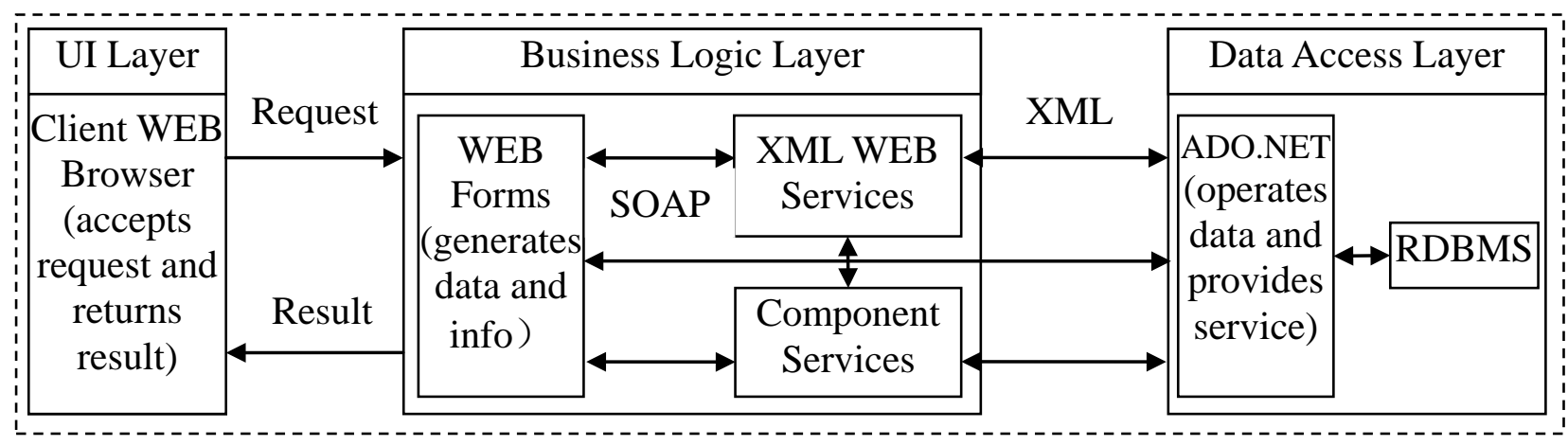

Fig. 1. ASP.NET system block diagram

ASP.NET technology has the following features: efficient operating performance, ASP.NET is common language runtime code compiled and ran on the server, using code page (.cs file) and the front page (.aspx file) isolated storage, ASP.NET applications can be like an application under Windows, generated DLL file and used caching mechanism allows better running of the page [6]; flexibility, ASP.NET has no direct relationship with any language, also does not depend on any Web browser, developers can choose their preferred language for creating rich Web applications, and also can develop using multiple languages, it has a high flexibility; simplicity, ASP.NET is development technology entirely based on object-oriented, making common tasks easy to perform; powerful development tool support, ASP.NET and Visual Studio.NET integrated together, they can use the powerful .NET development tools; security, ASP.NET allows to configure each application, allows the application to add the authentication, increased the security of the program [7]; customization and scalability, ASP.NET allows developers to add any component by own definition, these components can replace any sub-components in the ASP.NET runtime library[8].

\section{Database Technology}

Database technology is an important part of modern information science and technology, is the core of computer data processing and information management systems. The research of database technology solves the problem of effectively organizing and storing large amounts of data in the progress of computer information processing; reduces data storage redundant, achieves data sharing, guarantees data security and efficient retrievals data and processes data in the database system. The fundamental goal of database technology is to solve the problem of data sharing. Database technology involves many basic concepts, including information, data, data processing, database, database management systems, database systems and so on [9].

The enterprise information management system studied in this paper uses the SQL Server database technology, SQL Server is a relational database management system, and provides a convenient platform for current enterprise data management, its security and reliability has accepted by users [10]. Enterprise information management system database contains many table structures, such as user information table, employee information table, contract information table, customer information table, department information table and others. Therefore, the part of table structure in enterprise information management systems is shown in Table 1.

Table 1. Tables structure of in the database

\begin{tabular}{|c|c|c|c|c|c|c|c|}
\hline \multicolumn{4}{|c|}{ "User Information" Table } & \multicolumn{4}{|c|}{ "Employee Information" Table } \\
\hline 1 & ID & varchar & 20 & 1 & ID & varchar & 30 \\
\hline 2 & UserName & varchar & 10 & 2 & EmpName & varchar & 20 \\
\hline 3 & Password & varchar & 10 & 3 & Sex & varchar & 2 \\
\hline 4 & UserRole & varchar & 100 & 4 & HireTime & datetime & 8 \\
\hline \multicolumn{4}{|c|}{ "Department Information" Table } & 5 & Marriage & text & \\
\hline 1 & ID & varchar & 10 & 6 & Education & varchar & 100 \\
\hline
\end{tabular}




\begin{tabular}{llcc|clcc}
2 & DepartName & varchar & 50 & 7 & E-Mail & varchar & 20 \\
3 & CreatTime & datatime & & 8 & TelephoneNum & varchar & 30 \\
4 & Leader & varchar & 50 & 9 & DepartName & varchar & 50 \\
5 & Description & text & & $\ldots$ & $\ldots \ldots$ & $\ldots$ & $\ldots$
\end{tabular}

Database connection uses the ADO.NET technology, ADO.NET connects with database through Connection object to achieve. Connection objects are divided into SqlConnection and OleConnection, if the database is SQL Server, the Connection object is SqlConnection. Connection object using the DataSource property gets the data source, using the Open method opens data connection, and using CreateCommand methods creates and returns the Command object, using the Close method closes the database connection. For enterprise information management system studied in this paper, firstly creates a database named EnterpriseInfo, system and database on the same server, so you can connect to the database via web.config configuration file, the specific code as follows.

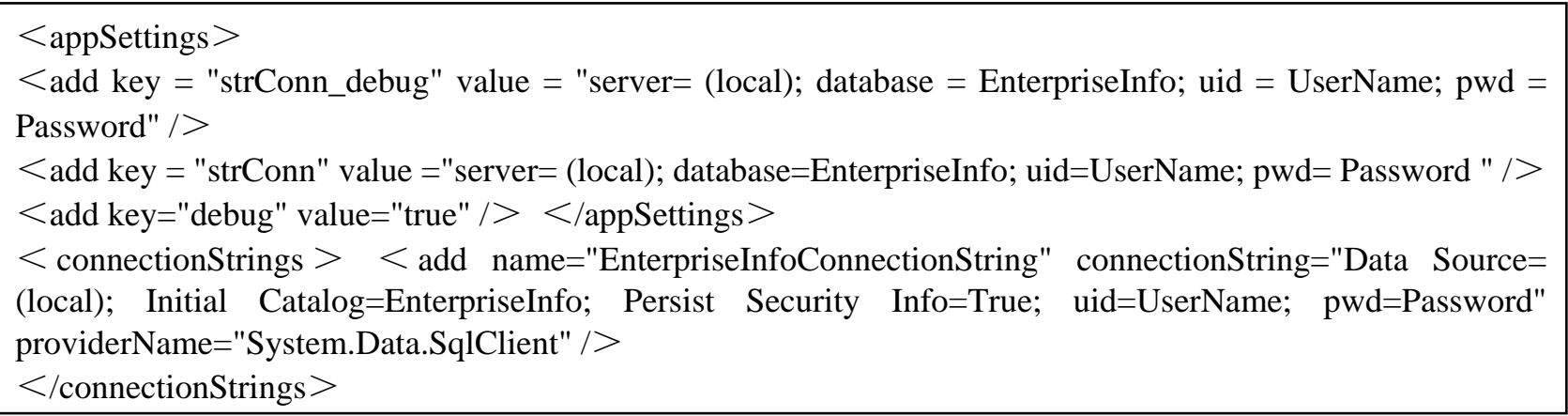

\section{Conclusion}

With the development of computer technology and the popularity of network, enterprise information management systems become more and more sophisticated, the information management system almost covers all sectors, and helps business managers to achieve business objectives and create the greatest benefits by the least amount of consumption. In the fierce market competition, enterprises must be promptly and accurately collect, master, develop and utilize information, finding their own direction of development, the first to open up the market and share market, timely and effectively to develop completive measures, thereby enhancing the competitiveness of enterprises. Requirement of era development will become higher and higher for information management system, in order to better meet the future needs, it also need to further analysis for the key technical of information management systems. Therefore, the researching result of this paper is important for the development of enterprise information management systems.

\section{References}

[1] L. E. Zhu, "Framework of Enterprise Information Management System Based on OSGI," Computer Era, vol. 29, no. 9, pp. 8-10, 2012.

[2] R. L. Zhou, "Application Research on Information Management System Key Technologies," Master's Degree of Chengdu University of Technology, 2006.

[3] W. Zhou, "Research on Enterprise Information Management System Key Technologies," Master's Degree of University of Electronic Science and Technology, 2005.

[4] Baidu Baike, "namespace," http://baike.baidu.com/view/6752.htm?fr=aladdin, 2014-10-28.

[5] J. Z. Fan, "Implementation Method of ASP.net-based the Three Layers," Computer Science, vol. 34, no. 4, pp. 289-290, 2007. 
[6] M. X. Zhu, "Design and Implementation of Secondary Vocational Schools Educational Administration System," Master's Degree of University of Electronic Science and Technology of China, 2011.

[7] F. Niu, "Design and Implementation of Automobile Sales Management System Based on ASP.NET," Master's Degree of University of Electronic Science and Technology of China, 2013.

[8] J. Sun, "Design and Implementation of ASP.NET-based Public Security Information System," Master's Degree of Tongji University, 2007.

[9] Baidu Baike, "namespace," http://baike.baidu.com/view/500320.htm?fr=aladdin, 2014-10-28.

[10] K. Liu, Q. F, Q. Zhang, " SQL Server 2008 from Entry to Master," Chemical Industry Press, 2009. 